\title{
SHCP: Soil Heat Calculator Program
}

\author{
Mohammad Valipour ${ }^{1}$, Seyyed Morteza Mousavi ${ }^{2}$, Reza Valipour ${ }^{3}$, Ehsan \\ Rezaei $^{4}$ \\ ${ }^{1}$ Department of Irrigation and Drainage Engineering, College of Abureyhan, University of Tehran, Tehran, Iran \\ ${ }^{2}$ Department of Hydrocarbon Reservoirs Engineering, Faculty of Oil Engineering (FOE), Islamic Azad \\ University, Science and Research Branch, Tehran, Iran \\ ${ }^{3}$ Department of Chemical Process Engineering, College of Chemical Engineering, Islamic Azad University, \\ Ahar Branch, Ahar, Iran \\ ${ }^{4}$ Department of Thermo-Fluids Engineering, College of Mechanical Engineering, Amirkabir University of \\ Technology, Tehran, Iran
}

\begin{abstract}
Usually the energy balance equation is used to estimate evapotranspiration. To calculating the potential evapotranspiration for long periods of time (more than a day), soil heat flux is assumed equal to zero. But in a catchment, the energy balance equation should be in terms of actual evapotranspiration is less than the potential. In this state, the amount of soil heat flux is not equal to zero. Therefore, for estimating the actual evapotranspiration, the soil heat flux calculation has great importance. In this paper, using coding in a visual basic program environment, a differential equation for the flow of water into the soil has been solved for soil heat flux calculating. Obtained results showed that the soil heat calculator program (SHCP) was an appropriate tool for calculating soil heat flux. According to the results the accuracy of the SHCP increased with over time. The amounts of $R 2$ after 1 hour, 2 hours, and 3 hours, were 0.991, 0.996, and 0.999, respectively, for soil heat flux at difference depths.
\end{abstract}

Keywords: Actual evapotranspiration, Energy balance equation, SHCP, Soil heat flux, Soil temperature

\section{Introduction}

Soil heat flux and thermal properties determination has been the aim of much research. Evett et al. [8] compared soil heat flux plates using the soil profile method for soil thermal diffusivity, conductivity, and heat flux. The overall method resulted in additional important knowledge including the water content dynamics in the near-surface soil profile and a soil-specific function relating thermal conductivity to soil water content and bulk density. Parker et al. [32] determined thermal diffusivity, heat capacity, and thermal conductivity using a flash method. Blumm and Opfermann [4] improved the mathematical modeling of flash measurements. The improved mathematical model was integrated in a nonlinear regression routine, allowing fitting of the experimental data to yield thermal diffusivity values with high accuracy. Casalegno et al. [5] measured thermal properties of a ceramic/metal joint by the laser flash method. This measurement was proposed as an innovative non-contact and qualitative investigation technique to assess the ceramic/metal joint integrity. Blumm et al. [3] measured selected thermophysical properties of the NPL certified reference material stainless steel 310. Payero et al. [33] estimated soil heat flux for alfalfa and clipped tall fescue grass successfully. Heitman et al. [12] indicated depth and magnitude of subsurface soil water evaporation using sensible heat measurements. Potential applications of this technique included location of the depth and magnitude of subsurface evaporation fluxes and estimation of stage 2-3 daily evaporation without requirements for a large fetch. Anadranistakis et al. [2] surveyed the importance of soil heat flux in the Penman-Montieth evapotranspiration equation. Variations in soil temperature and moisture alter the partitioning of sensible and latent heat from the surface and affect atmospheric boundary layer processes and regional circulation (Pan and Mahrt [31], Peters-Lidard et al. [34]). Ramos and Vieira [38] evaluated the ground surface enthalpy balance from bedrock temperatures (Livingston Island, Maritime Antarctic). The application of this method avoided error propagation induced by the heat exchange calculations from multiple sensors using the Fourier method. Hu and Feng [17] studied daily soil temperature datasets and soil temperature climatology of the contiguous United States. Significant warming was found in the winter and spring seasons. Priestley and Taylor [36] assessed surface heat flux and evaporation using large-scale parameters. P and Renuka [30] studied Temperature mapping, thermal diffusivity and subsoil heat flux at Kariavattom in Kerala. The diurnal variation of heat flux was influenced by soil moisture and incoming solar radiation. On dry days the net flow of heat was directed into the soil and on rainy days the reverse takes place. Ingersoll and Pankine [18] surveyed subsurface heat transfer on Enceladus (Conditions under which melting occurs) successfully.

Hofreiter [15] estimated soil heat flux for determination of evapotranspiration in ecosystems. This method allowed a better estimation of evapotranspiration, which is essentially used in agriculture, forestry, 
botany, soil science, geography, ecology, and geomorphology. Gan et al. [9] surveyed the effects of grazing intensity on soil thermal properties and heat flux under Leymus chinensis and Stipa grandis vegetation in Inner Mongolia, China. The results showed that grazing intensity affected the soil thermal properties and heat flux, but vegetation type was only verified to impact heat flux. Appropriate grazing intensity improved soil water and thermal regimes compared with the long-term un-grazed sites. Agam et al. [1] showed soil heat flux variability influenced by row direction in irrigated cotton. Loon et al. [25] calibrated soil heat flux sensors. Their corrections remain useful as a tool for designing soil heat flux sensors; also a positive relation existed between the magnitude of the correction and the inaccuracy of the measurement. Heitman et al. [11] researched latent heat in soil heat flux measurements. Results demonstrated the importance of including latent heat when attempts were made to link or extrapolate subsurface soil heat flux measurements to the surface soil heat flux. Wang and Bu-Zeid [47] presented a novel approach for the estimation of ground soil heat flux. Comparison of the results highlighted that the new model is robust and capable of preserving the good accuracy of the conventional approach with reduced input information. Kustas et al. [24] showed variability in soil heat flux from a mesquite dune site. Results from this study suggested that, to determine the number and location of sensors needed for estimating area-average soil heat flux in this type of landscape, one needs to account not only for the clustering of the vegetation cover but also micro-topography. Heusinkveld et al. [13] showed the role of soil heat flux in surface energy balance closure in an arid region. The results suggested that this method could be used as a reference surface soil heat flux measurement. Further examination of the energy balance closure was needed over a range of land surface types. Verhoef [45] presented a method for remote estimation of thermal inertia and soil heat flux for bare soil. This method potentially allowed area-average estimates of thermal inertia and soil heat flux to be derived from remote sensing, e.g. METEOSAT Second Generation, where the area was determined by the sensor's height and viewing angle. Tol [43] validated remote sensing of bare soil ground heat flux. The remote sensing model applied to the field radiometry performed well (slope of the regression against the validation target: $1.00, \mathrm{R} 2=0.96$ ). Good agreement was also found between the remote sensing method applied to field radiometry and to satellite data (slope of the regression: $0.79, \mathrm{R} 2=0.89$ ). Ogée et al. [29] presented a long-term study of soil heat flux under a forest canopy. Tyagi and Satyanarayana [44] modeled soil surface temperature and heat flux during the pre-monsoon season at two tropical stations. Successful validation of the methodology using Land Surface Processes Experiment (LASPEX) data revealed the estimation of soil surface temperature and heat flux at Kharagpur obtained was reasonable. Jacobs et al. [19] analyzed soil temperatures and soil heat fluxes in a grassland area in Netherlands. Murray and Verhoef [28] determined soil heat flux from remote measurements using a universal approach to calculate thermal inertia. This approach could be used to obtain area-averaged estimates of soil thermal inertia and soil heat flux, which is important for large-scale energy balance studies that employ aircraft or satellite data. Wang and Bras [48] estimated ground heat flux using surface soil temperature. Valipour [46] estimated ability of Box-Jenkins models in forecasting the reference potential evapotranspiration. By comparing root mean square error of the models, it was determined that Box-Jenkins models are appropriate approaches to evapotranspiration forecasting. Poulovassilis et al. [35] estimated heat flux using a contribution to the study of the water and energy balances of an irrigated soil profile. Qin et al. [37] simulated heat fluxes and surface temperature under bare soil environment using numerical solution of a complete surface energy balance model. Robin et al. [39] compared two types of soil heat fluxmeter (theoretical and field). They concluded that printed circuit transducers should be used when field calibration was not possible, or when the calibration was not stable following large soil thermal conductivity variations. The experiment also showed that the theory does not completely describe the interaction between calibration coefficients and soil properties. Graham et al. [10] calculated forest understory soil temperatures and heat flux using a Fourier model and scaled using a digital camera. Watts et al. [49] used a modified heat-meter method for determining soil heat flux. The method should serve to provide for a more accurate assessment of the energy budget of the earth's surface. Kimball and Jackson [21] determined soil heat flux using a null-alignment method. Horton and Wierenga [16] determined the mean soil temperature for evaluation of heat flux in soil. The probe methods were found to be more reliable for soil heat flux determinations than the soil heat flux plate method, and required fewer measurements and calculations for determination of soil heat flux than with the temperature integral method. Clothier et al. [6] estimated soil heat flux from net radiation during the growth of alfalfa. The results indicated that both crop height and spectral vegetation indices could be used to estimate soil heat flux from net radiation measurements. Sharratt et al. [41] estimated soil heat flux based on the finitedifference form of the transient heat flow equation. Kustas et al. [22] estimated the soil heat flux/net radiation ratio from spectral data. Silans et al. [42] corrected soil heat flux measurements to derive an accurate surface energy balance by the Bowen ratio method. Massman [26] corrected errors associated with soil heat flux measurements and estimating soil thermal properties from soil temperature and heat flux plate data. Kustas and Norman [23] evaluated soil and vegetation heat flux predictions using a simple two-source model with radiometric temperatures for a partial canopy cover. Hochstein and Bromley [14] measured heat flux from steaming ground successfully. Daughtry et al. [7] studied spectral estimates of net radiation and soil heat flux. 
Yang and Wang [50] presented a temperature prediction-correction method for estimating surface soil heat flux from soil temperature and moisture data. Jia et al. [20] compared sensible heat flux measurements by a large aperture scintillometer and eddy correlation methods.

The previous research shows that soil heat flux has been calculated in many studies, but an expensive method has been used in all of them such as field measurements or satellite images. In this paper, using programming in a visual basic environment, soil heat flux is calculated with good accuracy and compared with actual data that obtained in previous research (without any additional cost in both the estimating and comparing stages).

\section{Materials And Methods}

In Mehrabad synoptic station located at Tehran city in Iran. The station ranges between $35^{\circ}$, $41^{\prime}$ North latitude and $51^{\circ}, 19^{\prime}$ east longitude and is located in center of Tehran. The elevation of station is 1190.8 meter above sea level. In order to estimate reference potential evapotranspiration at the monthly scale, the station's meteorological data period from 1951-2000 has been gathered. Actually, the used data involved 3600 data that began from Janury1951and end in December 2000, include: mean temperature $\left(T_{\text {mean }}\right)$, wind speed (U), maximum temperature $\left(\mathrm{T}_{\max }\right)$, minimum temperature $\left(\mathrm{T}_{\min }\right)$, dew point temperature $\left(\mathrm{T}_{\mathrm{d}}\right)$, and sunshine hours recorded (n). Figure 1 shows position of Mehrabad synoptic station.

Usually the energy balance equation is used to estimate evapotranspiration as follows:

$\mathrm{E}=\mathrm{R}_{\mathrm{n}}-\mathrm{H}-\mathrm{G}$

Where $E$ is latent heat flux $\left(\mathrm{cal} / \mathrm{cm}^{2}\right), R_{n}$ is net radiation $\left(\mathrm{cal} / \mathrm{cm}^{2}\right), H$ is sensible heat $\left(\mathrm{cal} / \mathrm{cm}^{2}\right)$, and $G$ is soil heat flux $\left(\mathrm{cal} / \mathrm{cm}^{2}\right)$. The soil heat flux is the energy that is utilized in heating the soil. $G$ is positive when the soil is warming and negative when the soil is cooling. To calculating the potential evapotranspiration for long periods of time (more than a day), soil heat flux is assumed equal to zero. But in a catchment, the energy balance equation should be in terms of actual evapotranspiration which is less than its potential. In this state, the amount of soil heat flux is not equal to zero. Therefore, for estimating the actual evapotranspiration, soil heat flux calculating is of great importance. Equation (2) shows a one-dimension rate of soil heat flux:

$\mathrm{G}=-\mathrm{k}(\partial \mathrm{T} / \partial \mathrm{Z})$

Where $T$ is temperature $\left({ }^{\circ} \mathrm{C}\right), Z$ is soil depth $(\mathrm{cm})$, and $k$ is thermal conductivity $\left(\mathrm{cal} / \mathrm{s} / \mathrm{cm} /{ }^{\circ} \mathrm{C}\right)$ which depends on soil minerals, moisture, and soil pores. The negative sign in Equation (2) shows that soil hat flux is transferred from a place with more heat to a place with less heat. In Equation (2) due to the fact that heat radiation can be created from a wide area, the only vertical dimension is considered. For the calculationof soil heat flux, a differential equation for the flow of water into the soil has been solved as Equation (3):

$\partial \mathrm{T} / \partial \mathrm{t}=\mathrm{D}\left(\partial^{2} \mathrm{~T} / \partial \mathrm{Z}^{2}\right)$

Where $t$ is elapsed time (s) and $D$ is heat diffusivity $\left(\mathrm{cm}^{2} / \mathrm{s}\right)$ as follows:

$\mathrm{D}=\mathrm{k} / \mathrm{Cv}$

Where $C_{v}$ is heat capacity $\left(\mathrm{cal} / \mathrm{cm}^{3} /{ }^{\circ} \mathrm{C}\right)$. Table 1 shows some of the temporal properties for difference materials (Rosenberg et al., [40]).

Equation (3) is solved as follows:

$\operatorname{Tin}+1=\Delta \mathrm{t}(\mathrm{Ti}+1 \mathrm{n}-2 \mathrm{Tin}+\mathrm{Ti}-1 \mathrm{n}) \mathrm{D} /(\Delta \mathrm{Z}) 2+\mathrm{Tin}$

Where $n$ is a temporal step and $i$ is a spatial step. In Equation (5) courant number (Equation (6)) must be less than zero:

\section{$1-2 \mathrm{D} \Delta \mathrm{t} /(\Delta \mathrm{Z}) 2<0$}

The initial condition for solving Equation (5) is certain surface temperature and the boundary condition is to be a constant end temperature.

In this study, Equation (5) is solved by programming in a visual basic environment and the amount of soil heat flux is calculated using Equation (2). Figure 1 shows the SHCP environment.

Table 1. Some of the temporal properties for difference materials

\begin{tabular}{ccccc}
\hline Material & $\mathrm{C}_{\mathrm{p}}\left(\mathrm{cal} / \mathrm{gr} /{ }^{\circ} \mathrm{C}\right)$ & $\mathrm{C}_{\mathrm{v}}\left(\mathrm{cal} / \mathrm{cm}^{3} /{ }^{\circ} \mathrm{C}\right)$ & $\mathrm{k}\left(\mathrm{cal} / \mathrm{s} / \mathrm{cm} /{ }^{\circ} \mathrm{C}\right)$ & $\mathrm{D}\left(\mathrm{cm}^{2} / \mathrm{s}\right)$ \\
\hline Air & 0.640 & 0.00029 & 0.00062 & 0.00021 \\
Quartz & 0.175 & 0.46000 & 0.02000 & 0.04300 \\
Soil minerals & 0.175 & 0.46000 & 0.00700 & 0.01500 \\
Soil organics & 0.460 & 0.60000 & 0.00060 & 0.00100 \\
Water & 1.000 & 1.00000 & 0.00140 & 0.00140 \\
\hline
\end{tabular}

For comparing the obtained results with actual data, the soil temperatures were gathered for Oct. 30, 1999, a generally clear day in west-central Minnesota, Morris. A custom-made thermocouple temperature probe was used to acquire the soil temperature below the soil surface. On the probe, a thermocouple was placed from depths of $1.0 \mathrm{~cm}$ to $30.0 \mathrm{~cm}$ at one-centimeter intervals (McIntosh and Sharratt, 2001). 


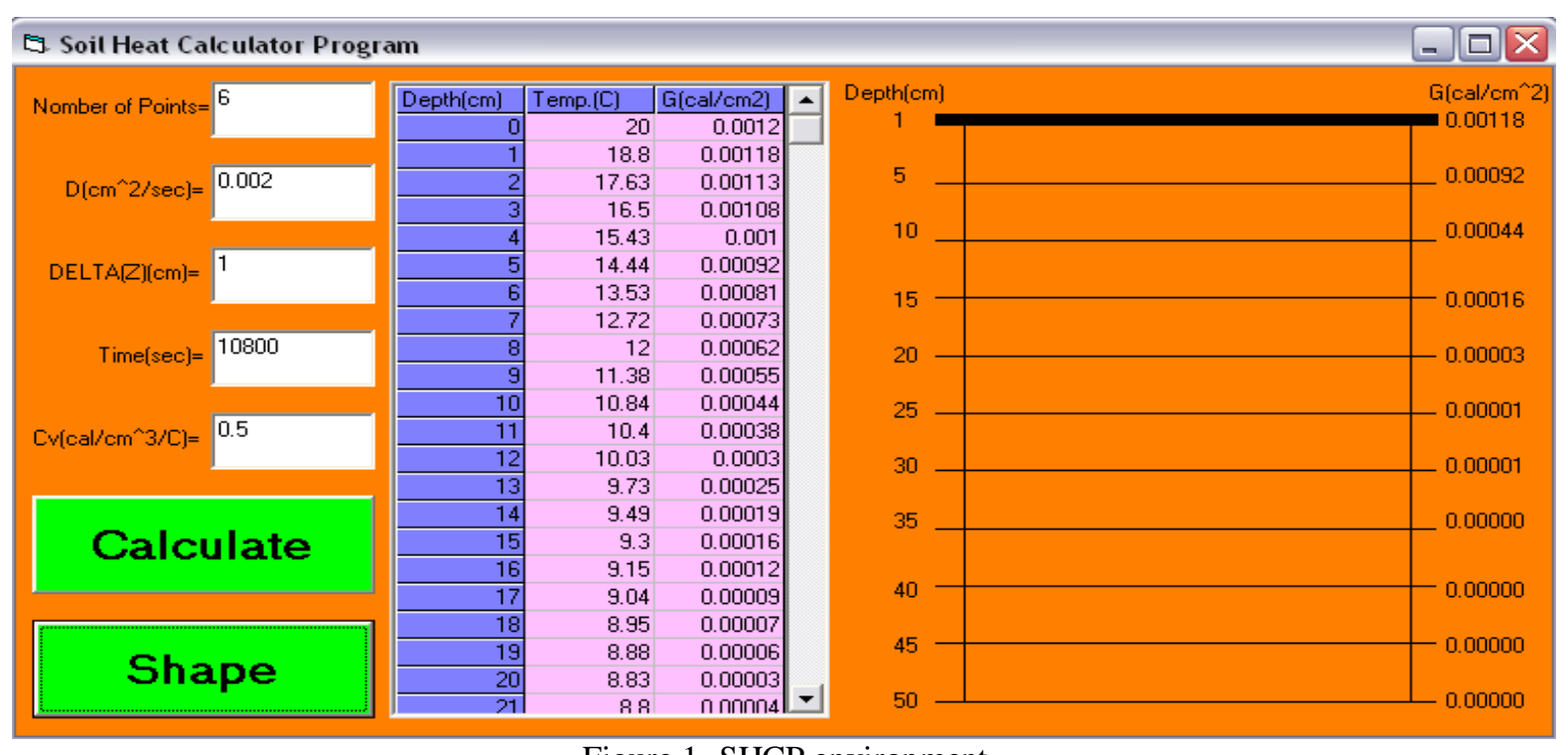

Figure 1- SHCP environment

\section{Results And Discussion}

Table 2 shows the obtained results for soil heat flux using measurement and the SHCP.

Table 2. Obtained results for soil heat flux $\left(\mathrm{cal} / \mathrm{cm}^{2}\right)$

\begin{tabular}{ccccccc}
\hline \multirow{2}{*}{ Soil depth $(\mathrm{cm})$} & \multicolumn{2}{c}{ After 1 hour } & \multicolumn{2}{c}{ After 2 hours } & \multicolumn{2}{c}{ After 3 hours } \\
& Observation & SHCP & Observation & SHCP & Observation & SHCP \\
\hline 1 & 0.00169 & 0.00172 & 0.00134 & 0.00136 & 0.00116 & 0.00118 \\
5 & 0.00081 & 0.00093 & 0.00090 & 0.00096 & 0.00089 & 0.00091 \\
10 & 0.00017 & 0.00023 & 0.00032 & 0.00036 & 0.00043 & 0.00044 \\
20 & 0.00002 & 0.00001 & 0.00002 & 0.00002 & 0.00003 & 0.00005 \\
30 & 0.00001 & 0.00001 & 0.00001 & 0.00001 & 0.00001 & 0.00001 \\
$\mathrm{R}^{2}$ & \multicolumn{2}{c}{0.991} & \multicolumn{3}{c}{0.996} & \\
\hline
\end{tabular}

According to Table 2 due to the balance over elapsed time, the amount of $\mathrm{R}^{2}$ after 3 hours was more than at other times. Figures 2-4 show the amount of soil heat flux after 1 hour, 2 hours, and 3 hours, respectively.

Figures 2-4 shows that the soil heat calculator program (SHCP) is an appropriate tool for calculating soil heat flux at different soil depths. This approach also is more accurate than similar previous research (Evett et al., 2012, Parker et al., 1961, Casalegno et al., 2010, Payero et al., 2005, Anadranistakis et al., 1997, Hu and Feng, 2003, Priestley and Taylor, 1972, Hofreiter, 2011, Agam et al., 2012, Heitman et al., 2010, Wang and Bu-Zeid, 2012, Tol, 2012, Wang and Bras, 1999, Clothier et al., 1986, Sharratt et al., 1992, and Daughtry et al., 1990). In addition, the cost of this study is less than all of the previous research.

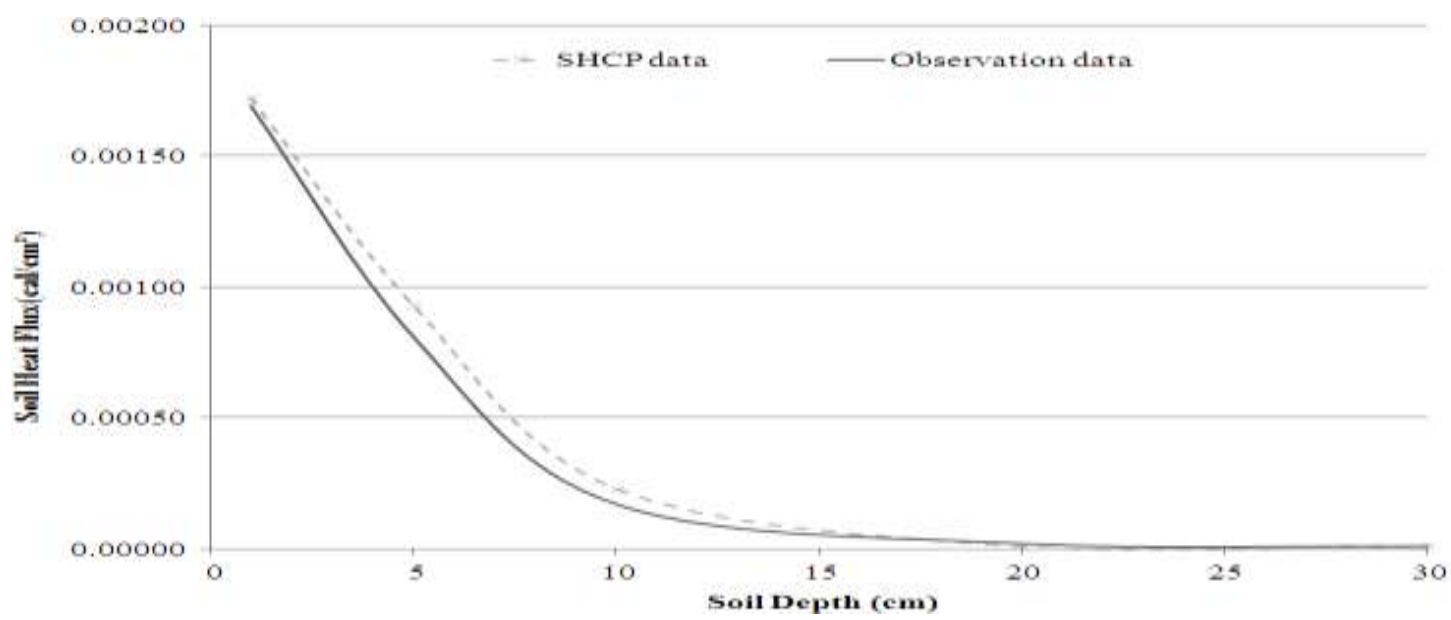

Figure 2. Amounts of soil heat flux after 1 hour 


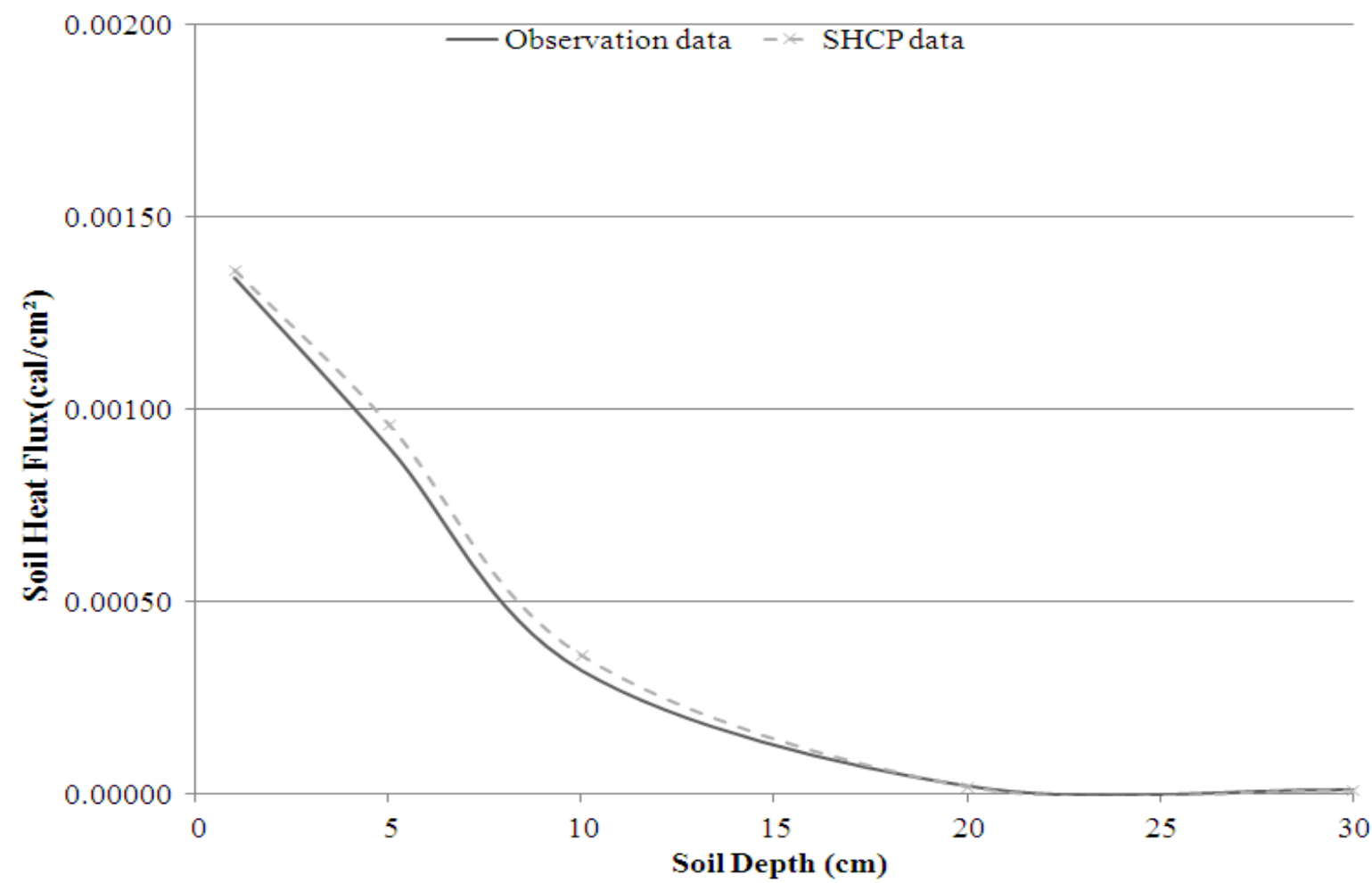

Figure 3. Amounts of soil heat flux after 2 hours

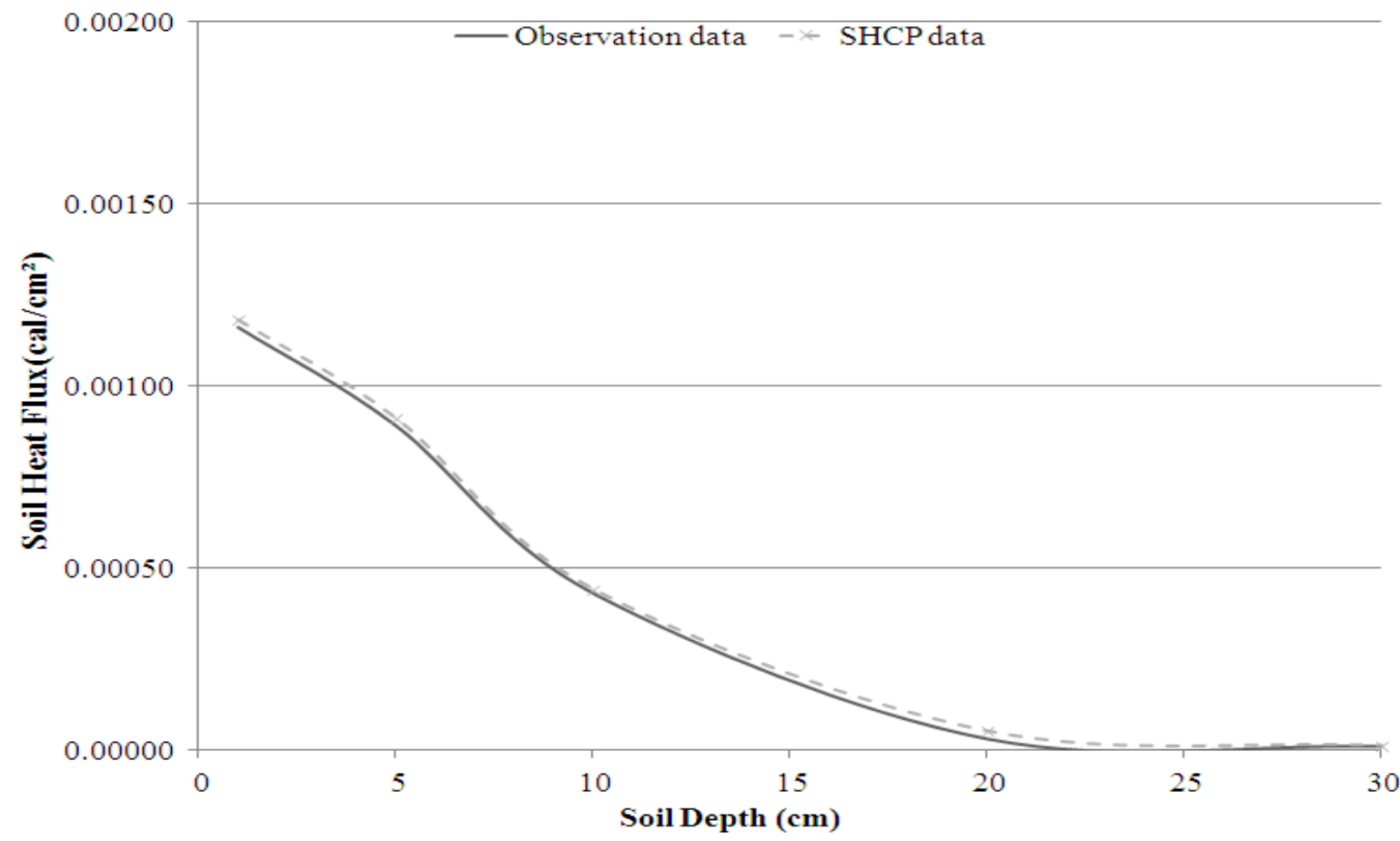

Figure 4. Amounts of soil heat flux after 3 hours

The surveying ability of the SHCP for more soil depths and under other climate conditions and irrigation situations, can be the subject of future studies.

\section{Conclusion}

In this paper, using programming in a visual basic environment, differential equation for the flow of water into the soil has been solved for calculating soil heat flux. The results showed that the soil heat calculator program (SHCP) was an appropriate tool for calculating soil heat flux. According to the results the accuracy of 
SHCP increased with time passed. The amounts of R2 after 1 hour, 2 hours, and 3 hours, were 0.991, 0.996, and 0.999 , respectively, for soil heat flux at difference depths.

\title{
V. Abbreviations
}

\author{
$E=$ Latent heat flux $\left(\mathrm{cal} / \mathrm{cm}^{2}\right)$ \\ $R_{n}=$ Net radiation $\left(\mathrm{cal} / \mathrm{cm}^{2}\right)$ \\ $H=$ Sensible heat $\left(\mathrm{cal} / \mathrm{cm}^{2}\right)$ \\ $G=$ Soil heat flux $\left(\mathrm{cal} / \mathrm{cm}^{2}\right)$ \\ $T=$ Temperature $\left({ }^{\circ} \mathrm{C}\right)$ \\ $Z=$ Soil depth $(\mathrm{cm})$ \\ $k=$ Thermal conductivity $\left(\mathrm{cal} / \mathrm{s} / \mathrm{cm} /{ }^{\circ} \mathrm{C}\right)$ \\ $t=$ Elapsed time (s) \\ $D=$ Heat diffusivity $\left(\mathrm{cm}^{2} / \mathrm{s}\right)$ \\ $C_{v}=$ Heat capacity $\left(\mathrm{cal} / \mathrm{cm}^{3} /{ }^{\circ} \mathrm{C}\right)$ \\ $n=$ Temporal step \\ $i=$ Spatial step \\ $C_{p}=$ Specific heat $\left(\mathrm{cal} / \mathrm{gr} /{ }^{\circ} \mathrm{C}\right)$
}

\section{References}

[1] Agam N., W. P. Kustas, S. R. Evett, P. D. Colaizzi, M. H. Cosh, L. G. McKee, 2012. Soil heat flux variability influenced by row direction in irrigated cotton, Advances in Water Resources, doi: http://dx.doi.org/10.1016/j.advwatres.2012.07.017

[2] Anadranistakis M., A. Liakatas, S. Alexandris, S. Aggelides, P. Kerkides, S. Rizos, and A. Poulovassilis, 1997. SOIL HEAT FLUX IN THE PENMAN-MONTEITH EVAPOTRANSPIRATION EQUATION, ISHS Acta Horticulturae 449: II International Symposium on Irrigation of Horticultural Crops

[3] Blumm J., A. Lindemann, B. Niedrig and R. Campbell, 2007. Measurement of Selected Thermophysical Properties of the NPL Certified Reference Material Stainless Steel 310, International Journal of Thermophysics, 28 (2), p. 674-682. doi: 10.1007/s10765007-0177-z

[4] Blumm J., J. Opfermann, 2002. Improvement of the mathematical modeling of flash measurements, High Temperatures - High Pressures, 34 (5), p. 515-521. doi:10.1068/htjr061

[5] Casalegno V., P. Vavassori, M. Valle, M. Ferraris, M. Salvo, G. Pintsuk, 2010. Measurement of thermal properties of a ceramic/metal joint by laser flash method, Journal of Nuclear Materials, 407 (2), p. 83-87. doi: http://dx.doi.org/10.1016/j.jnucmat.2010.09.032

[6] Clothier B. E., K. L. Clawson, P. J. P. Jr, M. S. Moran, R. J. Reginato and R. D. Jackson, 1986. Estimation of soil heat flux from net radiation during the growth of alfalfa, Agricultural and Forest Meteorology, 37 (4), p. 319-329. doi: http://dx.doi.org/10.1016/01681923(86)90069-9

[7] Daughtry C.S.T., W.P. Kustas, M.S. Moran, P.J. Pinter Jr., R.D. Jackson, P.W. Brown, W.D. Nichols and L.W. Gay, 1990. Spectral estimates of net radiation and soil heat flux, 32 (2-3), p. 111-124. doi: http://dx.doi.org/10.1016/0034-4257(90)90012-B

[8] Evett S. R., N. Agam, W. P. Kustas, P. D. Colaizzi and R. C. Schwartz, 2012. Soil profile method for soil thermal diffusivity, conductivity and heat flux: Comparison to soil heat flux plates, Advances in Water Resources, doi: http://dx.doi.org/10.1016/j.advwatres.2012.04.012

[9] Gan L., X. Peng, S. Peth and R. Horn, 2012. Effects of grazing intensity on soil thermal properties and heat flux under Leymus chinensis and Stipa grandis vegetation in Inner Mongolia, China, Soil and Tillage Research, 118, p. 147-158. doi: http://dx.doi.org/10.1016/j.still.2011.11.005

[10] Graham E. A., Y. Lam and E. M. Yuen, 2010. Forest understory soil temperatures and heat flux calculated using a Fourier model and scaled using a digital camera, Agricultural and Forest Meteorology, 150 (4), p. 640-649. doi: http://dx.doi.org/10.1016/j.agrformet.2010.02.005

[11] Heitman J. L., R. Horton, T. J. Sauer, T. S. Ren, X. Xiao, 2010. Latent heat in soil heat flux measurements, Agricultural and Forest Meteorology, 150 (7-8), p. 1147-1153. doi: http://dx.doi.org/10.1016/j.agrformet.2010.04.017

[12] Heitman J. L., X. Xiao, R. Horton, and T. J. Sauer, 2008. Sensible heat measurements indicating depth and magnitude of subsurface soil water evaporation, WATER RESOURCES RESEARCH, 44, W00D05, 7 PP., doi:10.1029/2008WR006961

[13] Heusinkveld B. G., A. F. G. Jacobs, A. A. M. Holtslag and S. M. Berkowicz, 2004. Surface energy balance closure in an arid region: role of soil heat flux, Agricultural and Forest Meteorology, 122 (1-2), p. 21-37. doi: http://dx.doi.org/10.1016/j.agrformet.2003.09.005

[14] Hochstein M. P. and C. J. Bromley, 2005. Measurement of heat flux from steaming ground, Geothermics, 34 (2), p. 131-158. doi: http://dx.doi.org/10.1016/j.geothermics.2004.04.002

[15] Hofreiter M., 2011. ESTIMATION OF THE SOIL HEAT FLUX FOR DETERMINATION OF EVAPOTRANSPIRATION IN ECOSYSTEMS, 15th International Research/Expert Conference "Trends in the Development of Machinery and Associated Technology" TMT 2011, Prague, Czech Republic, p. 425-428.

[16] Horton R. and P. J. Wierenga, 1983. Determination of the mean soil temperature for evaluation of heat flux in soil, Agricultural Meteorology, 28 (4), p. 309-319. doi: http://dx.doi.org/10.1016/0002-1571(83)90008-0

[17] Hu Q and S. Feng, 2003. A Daily Soil Temperature Dataset and Soil Temperature Climatology of the Contiguous United States, American Meteorological Society, 42, p. 1139-1156.

[18] Ingersoll A. P. and A. A. Pankine, 2010. Subsurface heat transfer on Enceladus: Conditions under which melting occurs, Icarus, 206, p. 594-607. doi:10.1016/j.icarus.2009.09.015 
[19] Jacobs A. F. G., B. G. Heusinkveld and A. A. M. Holtslag, 2011. Long-term record and analysis of soil temperatures and soil heat fluxes in a grassland area, The Netherlands, Agricultural and Forest Meteorology, 151 (7), p. 774-780. doi: http://dx.doi.org/10.1016/j.agrformet.2011.01.002

[20] Jia X., X. Zhang and D. D. Steele, 2009. Comparison of Sensible Heat Flux Measurements by a Large Aperture Scintillometer and Eddy Correlation Methods, World Environmental and Water Resources Congress 2009: Great Rivers, p. 1-8. doi: http://dx.doi.org/10.1061/41036(342)422

[21] Kimball B. A. and R. D. Jackson, 1975. Soil heat flux determination: a null-alignment method, Agricultural Meteorology, 15 (1), p. 1-9. doi: http://dx.doi.org/10.1016/0002-1571(75)90014-X

[22] Kustas W. P. and C. S. T. Daughtry, 1990. Estimation of the soil heat flux/net radiation ratio from spectral data, Agricultural and Forest Meteorology, 49 (3), p. 205-223. doi: http://dx.doi.org/10.1016/0168-1923(90)90033-3

[23] Kustas W. P. and J. M. Norman, 1999. Evaluation of soil and vegetation heat flux predictions using a simple two-source model with radiometric temperatures for partial canopy cover, Agricultural and Forest Meteorology, 94 (1), p. 13-29. doi: http://dx.doi.org/10.1016/S0168-1923(99)00005-2

[24] Kustas W. P., J. H. Prueger, J. L. Hatfield, K. Ramalingam and L. E. Hipps, 2000. Variability in soil heat flux from a mesquite dune site, Agricultural and Forest Meteorology, 103 (3), p. 249-264. doi: http://dx.doi.org/10.1016/S0168-1923(00)00131-3

[25] Loon W. K. P. V., H. M. H. Bastings and E. J. Moors, 1998. Calibration of soil heat flux sensors, Agricultural and Forest Meteorology, 92 (1), p. 1-8. doi: http://dx.doi.org/10.1016/S0168-1923(98)00090-2

[26] Massman W.J., 1992. Correcting errors associated with soil heat flux measurements and estimating soil thermal properties from soil temperature and heat flux plate data, Agricultural and Forest Meteorology, 59 (3-4), p. 249-266. doi: http://dx.doi.org/10.1016/0168-1923(92)90096-M

[27] McIntosh G and B. S. Sharratt, 2001. Thermal Properties of Soil, THE PHYSICS TEACHER, 39, p. 458-460.

[28] Murray T. and A. Verhoef, 2007. Moving towards a more mechanistic approach in the determination of soil heat flux from remote measurements: I. A universal approach to calculate thermal inertia, Agricultural and Forest Meteorology, 147 (1-2), p. 80-87. doi: http://dx.doi.org/10.1016/j.agrformet.2007.07.004

[29] Ogée J., E. Lamaud, Y. Brunet, P. Berbigier and J. M. Bonnefond, 2001. A long-term study of soil heat flux under a forest canopy, Agricultural and Forest Meteorology, 106 (3), p. 173-186. doi: http://dx.doi.org/10.1016/S0168-1923(00)00214-8

[30] P T. C. and G Renuka, Temperature mapping, thermal diffusivity and subsoil heat flux at Kariavattom of Kerala, Proc. Indian Acad. Sci. (Earth Planet. Sci.), 111 (1), p. 79-85.

[31] Pan H. L. and L. Mahrt, 1987. Interaction between soil hydrology and boundary-layer development, Bound.-Layer Meteor., 38, p. $185-202$.

[32] Parker W. J., R. J. Jenkins, C. P. Butler, and G. L. Abbott, 1960. Flash Method of Determining Thermal Diffusivity, Heat Capacity, and Thermal Conductivity, Journal of Applied Physics, 32 (90), doi: http://dx.doi.org/10.1063/1.1728417

[33] Payero J. O., C. M. U. Neale, and J. L. Wright, 2005. ESTIMATING SOIL HEAT FLUX FOR ALFALFA AND CLIPPED TALL FESCUE GRASS, Applied Engineering in Agriculture, 21(3), p. 401-409.

[34] Peters-Lidard C. D., E. Blackburn, X. Liang, and E. F. Wood, 1998. The effect of soil thermal conductivity parameterization on surface energy fluxes and temperatures. J. Atmos. Sci., 55, p. 1209-1224.

[35] Poulovassilis A., P. Kerkides, S. Alexandris and S. Rizos, 1998. A contribution to the study of the water and energy balances of an irrigated soil profile: A. Heat flux estimates, Soil and Tillage Research, 45 (1-2), p. 189-198. doi: http://dx.doi.org/10.1016/S09333630(97)00008-1

[36] Priestley C. H. B. and R. J. Taylor, 1972. On the Assessment of Surface Heat Flux and Evaporation Using Large-Scale Parameters, Monthly Weather Review, 100 (2), p. 81-92.

[37] Qin Z., P. Berliner and A. Karnieli, 2002. Numerical solution of a complete surface energy balance model for simulation of heat fluxes and surface temperature under bare soil environment, Applied Mathematics and Computation, 130 (1), p. 171-200. doi: http://dx.doi.org/10.1016/S0096-3003(01)00089-3

[38] Ramos M. and G. Vieira, 2009. Evaluation of the ground surface Enthalpy balance from bedrock temperatures (Livingston Island, Maritime Antarctic), The Cryosphere, 3, p. 133-145.

[39] Robin P., P. Cellier and G. Richard, 1997. Theoretical and field comparison of two types of soil heat fluxmeter, Soil Technology, 10 (3), p. 185-206. doi: http://dx.doi.org/10.1016/S0933-3630(96)00125-0

[40] Rosenberg, N. J., B. L. Blad and S. B. Verma, 1983. Microclimate: The Biological Environment, Wiley-Interscience, 2 edition, ISBN: 0471060666, $528 \mathrm{p}$

[41] Sharratt B. S., G. S. Campbell and D. M. Glenn, 1992. Soil heat flux estimation based on the finite-difference form of the transient heat flow equation, Agricultural and Forest Meteorology, 61 (1-2), p. 95-111. doi: http://dx.doi.org/10.1016/0168-1923(92)90027-2

[42] Silans A. P. D., B. A. Monteny, J. P. Lhomme, 1997. The correction of soil heat flux measurements to derive an accurate surface energy balance by the Bowen ratio method, Journal of Hydrology, 188-189, p. 453-465. doi: http://dx.doi.org/10.1016/S00221694(96)03187-3

[43] Tol C. V. D., 2012. Validation of remote sensing of bare soil ground heat flux, Remote Sensing of Environment, 121, p. $275-286$. doi: http://dx.doi.org/10.1016/j.rse.2012.02.009

[44] Tyagi B. and A. N. V. Satyanarayana, 2010. Modeling of soil surface temperature and heat flux during pre-monsoon season at two tropical stations, Journal of Atmospheric and Solar-Terrestrial Physics, 72 (2-3), p. 224-233. doi: http://dx.doi.org/10.1016/j.jastp.2009.11.015

[45] Verhoef A., 2004. Remote estimation of thermal inertia and soil heat flux for bare soil, Agricultural and Forest Meteorology, 123 (3-4), p. 221-236. doi: http://dx.doi.org/10.1016/j.agrformet.2003.11.005

[46] Valipour, M., 2012. Ability of Box-Jenkins Models to Estimate of Reference Potential Evapotranspiration (A Case Study: Mehrabad Synoptic Station, Tehran, Iran), IOSR Journal of Agriculture and Veterinary Science (IOSR-JAVS), 1 (5), 1-11. http://iosrjournals.org/iosr-javs/papers/vol1-issue5/A0150111.pdf

[47] Wang Z. H. and E. Bou-Zeid, 2012. A novel approach for the estimation of soil ground heat flux, Agricultural and Forest Meteorology, 154-155, p. 214-221. doi: http://dx.doi.org/10.1016/j.agrformet.2011.12.001

[48] Wang J. and R. L Bras, 1999. Ground heat flux estimated from surface soil temperature, Journal of Hydrology, 216 (3-4), p. $214-$ 226. doi: http://dx.doi.org/10.1016/S0022-1694(99)00008-6

[49] Watts D. B., E. T. Kanemasu and C. B. Tanner, 1990. Modified heat-meter method for determining soil heat flux, Agricultural and Forest Meteorology, 49 (4), p. 311-330. doi: http://dx.doi.org/10.1016/0168-1923(90)90004-P

[50] Yang K. and J.M. Wang, 2008. A temperature prediction-correction method for estimating surface soil heat flux from soil temperature and moisture data, Science in China Series D: Earth Sciences, 51 (5), p. 721-729. 